\title{
Commentary: Reinventing the wheel: Off- versus on-pump redo coronary artery bypass grafting
}

Tamer Attia, MD, MSc, PhD, and Michael E. Halkos, MD, MSc

\author{
From the Division of Cardiothoracic Surgery, Emory University School of Medicine, Atlanta, Ga. \\ Disclosures: Dr Halkos serves as an advisory board member for Medtronic, Inc. Dr Attia has nothing to disclose \\ with regard to commercial support. \\ Received for publication April 29, 2019; accepted for publication April 30, 2019; available ahead of print June 27, \\ 2019. \\ Address for reprints: Tamer Attia, MD, MSc, PhD, Division of Cardiothoracic Surgery, Emory University School \\ of Medicine, 1365A Clifton Rd, NE, Suite 2200, Atlanta, GA 30322 (E-mail: tattia@emory.edu). \\ J Thorac Cardiovasc Surg 2020;159:457-8 \\ $0022-5223 / \$ 36.00$ \\ Copyright (C) 2019 by The American Association for Thoracic Surgery \\ https://doi.org/10.1016/j.jtcvs.2019.04.100
}

The use of off-pump techniques for coronary artery bypass grafting (CABG) peaked in the 1990s but continues to decline. In 2016 , only $13 \%$ of all CABG surgery were performed off-pump. ${ }^{1}$ It was originally introduced to avoid the adverse effects of cardiopulmonary bypass and minimize aortic manipulation. However, multiple trials have failed to show a clear advantage for the off-pump CABG. The CABG Off- or On-Pump Revascularization Study (CORONARY) did not show a significant difference in the composite outcome of death, stroke, renal failure, myocardial infarction, and the need for repeat revascularization up to 5 years. $^{2}$ However, patients who had off-pump CABG received fewer grafts and were more likely to receive incomplete revascularization. Other randomized controlled trials (German Off-Pump Coronary Artery Bypass Grafting in Elderly Patients [GOPCABE ${ }^{3}$ ] and Randomized On/Off Bypass $\left[\mathrm{ROOBY}^{4}\right]$ ) supported these results. The ROOBY trial even reported lower overall survival at 5 years in patients who had off-pump CABG. Although there were clear limitations with this study related to the surgeons' experience with the off-pump technique, the results of this initial randomized trial were corroborated by the subsequent trials. ${ }^{5}$ Furthermore, these randomized trials minimized selection bias, which plague most of the observational studies, many of which have shown a benefit of off-pump compared with on-pump CABG.

The number of reoperative $\mathrm{CABG}$ procedures has also progressively declined. This is largely because of the increasing use of percutaneous coronary intervention in this patient population. In addition, increased adoption of internal thoracic artery grafting and postoperative optimal medical therapy has decreased the need for repeat revascularization. ${ }^{6}$ Reoperative $\mathrm{CABG}$ presents various challenges when compared with primary CABG. Patients are usually older, with more complex coronary artery disease and more comorbidities. Proximity of cardiac structures to the sternum, mediastinal adhesions, partially thrombosed vein grafts, and suboptimal coronary targets either from optimal targets.

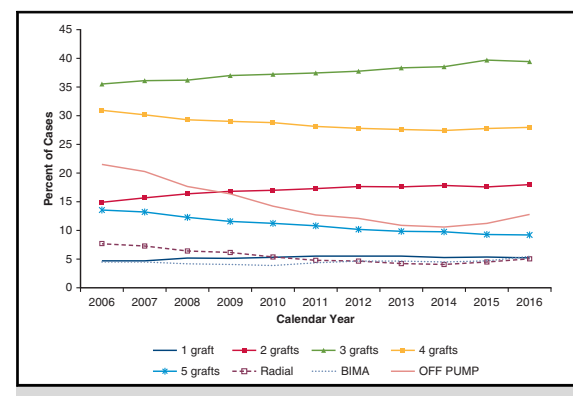

CABG: trends in conduits use and procedures performed off-pump (2006-2016). 'Radial, Radial artery graft; BIMA, bilateral internal mammary artery grafts.

\section{Central Message}

With lack of evidence of benefit from randomized trials, on-pump, compared with off-pump CABG, should continue to be considered the standard of care for primary and reoperative CABG.

See Article page 447.

advanced coronary disease and calcification or previous stenting are important considerations during reoperation. An on-pump strategy facilitates dissection and exposure of left-sided coronary targets, can potentially minimize manipulation of old grafts, and is more likely to achieve complete revascularization, especially in patients with sub-

There is likely a role for an off-pump strategy in selected patients, such as those with a porcelain aorta or a greater risk of stroke. However, it is difficult to justify routine use of a more challenging technique (off-pump) for a more difficult operation that has been shown repeatedly in randomized clinical trials to offer no significant advantage.

From the randomized and observational trials that have compared off- versus on-pump CABG, there is one point with which most surgeons would agree: to have comparable results with off- versus on-pump CABG, surgeons have to be experienced and routinely use off-pump techniques. The best results with off-pump CABG come from centers with extensive experience, which are not necessarily generalizable to all coronary surgeons. As the authors of the current manuscript have shown, results can be good in reoperative $\mathrm{CABG}$ in experienced hands and in selected patients. For the $>80 \%$ of surgeons who mostly perform 
on-pump CABG, the reoperative patient should be approached with the same methods as those undergoing primary CABG.

\section{References}

1. D'Agostino RS, Jacobs JP, Badhwar V, Fernandez FG, Paone G, Wormuth DW, et al. The Society of Thoracic surgeons adult cardiac surgery database: 2018 update on outcomes and quality. Ann Thorac Surg. 2018;105:15-23.

2. Lamy A, Devereaux PJ, Prabhakaran D, Taggart DP, Hu S, Straka Z, et al. Fiveyear outcomes after off-pump or on-pump coronary-artery bypass grafting. $N$ Engl J Med. 2016;375:2359-68.
3. Diegeler A, Börgermann J, Kappert U, Breuer M, Böning A, Ursulescu A, et al. Off-pump versus on-pump coronary-artery bypass grafting in elderly patients. $N$ Engl J Med. 2013;368:1189-98.

4. Shroyer AL, Hattler B, Wagner TH, Collins JF, Baltz JH, Quin JA, et al. Five-year outcomes after on-pump and off-pump coronary-artery bypass. $N$ Engl J Med. 2017;377:623-32.

5. Taggart DP, Puskas JD. Correspondence to the editor: five-year outcomes after on-pump and off-pump coronary-artery bypass. N Engl J Med. 2017;377: 1894-6.

6. Taggart DP, Altman DG, Gray AM, Lees B, Gerry S, Benedetto U, et al. Randomized trial of bilateral versus single internal-thoracic-artery grafts. $N$ Engl J Med. 2016;375:2540-9. 